\title{
IMPORTANCE OF TEACHING ENVIRONMENTAL CONTAMINATION AND DECONTAMINATION IN HUMAN HEALTH SCIENCE DEGREES
}

\author{
A. Peña-Fernández ${ }^{1}$, M.C. Lobo-Bedmar' ${ }^{2}$, M.A. Peña ${ }^{3}$ \\ ${ }^{1}$ Faculty of Health and Life Sciences, De Montfort University (UNITED KINGDOM) \\ ${ }^{2}$ Departamento de Investigación Agroambiental. IMIDRA (SPAIN) \\ ${ }^{3}$ Departamento de Ciencias Biomédicas Universidad de Alcalá (SPAIN)
}

\begin{abstract}
A novel short training in environmental toxicology, risk assessment and decontamination was created in the specialty of "Industrial Pharmacy and Galenic" at the University of Alcalá (UAH, Spain) in 201314 to provide postgraduate pharmacists with basic skills, tools and knowledge to decontaminate environments affected by chemical accidents. These students completed a highly specialised research-led workshop (training) to decontaminate an open water system affected by a chemical industry spill accident using the "UK Recovery Handbook for Chemical Incidents" (UKRHCl; [1]). The $\mathrm{UKRHCl}$ has been developed by Public Health England (PHE) and includes innovative methodology to select appropriate decontamination options and techniques to tackle environments impacted by chemicals. This training was modified in 2015/16 to introduce the innovative PHE virtual resource "Chemical Recovery Navigation Tool" (CRNT; [2]) that follows the same methodology and resources described in the UKRHCl. Comprehensive student feedback, including a SWOT analysis (strengths, weaknesses, opportunities and threats), was collected to investigate the changes implemented in our training. The modifications undertaken raised high levels of student satisfaction. Briefly, $100 \%$ students reported that the CRNT facilitated the understanding of the training and the selection of recovery options to respond to the case scenario proposed. Students described as a strength that the workshop was very interesting, interactive and novel and its execution in English (as the training was delivered at the Spanish university $U A H$ ). The possibility of working in environmental toxicology and decontamination was described as an opportunity. Students highlighted as weaknesses and threat its low relation with the pharmaceutical industry and brief duration (5 hours). This academic course (2016/17), a comprehensive modification has been undertaken at De Montfort University (DMU, UK) to adapt this novel training to a range of different human health science programmes, including master's students attending the MSc. Advanced Biomedical Science programme at DMU and undergraduate Pharmacy students at the University of San Pablo CEU (USP-CEU, Spain). An Erasmus+ mobility grant for academics was satisfactorily used to validate this short training at USP-CEU earlier in 2017. A specific feedback-questionnaire distributed in both academic arenas provided the following results: $85.7 \%$ (USP-CEU) and 50\% (DMU) neither agree nor disagree with a statement about enjoyment of the workshop provided. $83 \%$ of the master's students (DMU) and $86 \%$ of undergraduate students (USP-CEU) reported that they learnt how to select appropriate recovery options to decontaminate the open water and urban environments proposed. Finally, $42.9 \%(57.1 \%$ neither agree nor disagree) and $83 \%$ of students recommended the incorporation of more, similar training in each programme respectively (USP-CEU and DMU). The short training described in this paper has shown to be effective in improving students' knowledge and skills to restore environments impacted by chemical agents. We consider that all human health undergraduate programmes should teach some topics on environmental toxicology and decontamination due to the increasing use of toxic and carcinogenic chemicals by people and industries around the world.
\end{abstract}

Keywords: environmental toxicology and decontamination, training, undergraduate and postgraduate students, chemical agents.

\section{INTRODUCTION}

There is an increasing need for toxicological knowledge when working in industry, public and the private sectors. In particular the health sector is attracting more workers with skills in environmental health due to the large burden of disease and mortality caused by environmental pollutants [3-5]. Moreover, recent chemical incidents (release of chemical hazards) such as the fire affecting a large tire landfill in Toledo (Spain, 2016) [6] has highlighted the importance of training future health care professionals how to respond to these events due to their long-term adverse effects on human health. Environmental toxicology is a multidisciplinary field of science concerned with the assessment of the 
harmful effects of chemical, biological and physical agents in the environment on living organisms. To prevent or minimise deleterious effects on human health due to environmental pollutants, environmental recovery and restoration are important tools to respond to chemical incidents or to tackle environments impacted by chemicals $[7,8]$.

Therefore, the study of environmental health and toxicology should be part of the education of all fullyformed professionals in health sciences and anyone that wants to work in the chemical and/or pharmaceutical industries [9]. Our response was to create novel, short training in environmental toxicology, risk assessment and decontamination at the University of Alcalá (UAH, Spain) in 2013-14 to provide postgraduate pharmacists enrolled in the specialty of "Industrial Pharmacy and Galenic" with basic skills, tools and knowledge to develop an initial intervention to recover and restore environments affected by chemical accidents. We have described this novel training in PeñaFernández et al. (2015) [9]. Briefly, these students completed a highly specialised research-led workshop (training) to decontaminate an open water system affected by a pharmaceutical industry spill accident using the "UK Recovery Handbook for Chemical Incidents" (UKRHCl; [1]). The UKRHCI has been developed by Public Health England (PHE) and includes innovative methodology to select appropriate decontamination options and techniques to tackle environments impacted by chemicals. This training was modified in 2015/16 to introduce the innovative PHE virtual resource "Chemical Recovery Navigation Tool" (CRNT; [2]) that follows the same methodology and resources described in the UKRHCl. This methodology aids users in selecting appropriate protection and recovery options as a function of the physicochemical properties of the chemical(s) involved (pharmaceutical drugs) and the affected environment $[1,7,8]$. To overcome time constraints, students were provided with a small workbook with detailed information about the physicochemical properties of the contaminants involved in the case scenario.

Following this training, we have recently created basic competences that any human health science student should have, to initially tackle chemical incidents following major competences recently identified by the European Commission [10]. One of those competences is related to be able to tailor an appropriate environmental recovery and restoration approach to protect public health in the aftermath of any of these events [11].

\section{METHODOLOGY}

The aims of this study were: a) to determine if the updates made to the original training, including the use of the novel tool CRNT, enhance students' engagement, understanding and satisfaction; $b$ ) to investigate if this training, developed for postgraduate pharmacists at $\mathrm{UAH}$, would be applicable to other human health science students from postgraduate and undergraduate programmes.

To meet these objectives, we have collected comprehensive feedback from postgraduate pharmacists when delivering the updated training in 2015/16. Moreover, we have updated and adapted this training to deliver it during this academic course $2016 / 17$ to:

- Undergraduate Pharmacy students $(n=14)$ enrolled in the module on Toxicology (fourth year module) at the University of San Pablo CEU (USP-CEU, Spain). The pharmacy degree programme at University of San Pablo CEU is 5 years long and is validated by the Spanish Agency for Quality Assessment and Accreditation (ANECA). An Erasmus+ mobility grant for academics was satisfactorily used to deliver this short training at USP-CEU earlier in 2017. More details about the specific training deliver to these undergraduate students is provided in Peña-Fernández et al. (2017) [10].

- Postgraduate students enrolled $(n=9)$ in the MSc. Advanced Biomedical Science at De Montfort University (DMU, UK). More details about the specific training implemented at DMU will be published in due course in [11].

Finally, we have used qualitative and quantitative approaches to gain information from students from both educational arenas about their experience with the training, with a focus on their understanding and acquisition of skills/knowledge. The analysis of these data could be used as a "validation" of the training to develop future short courses on environmental toxicology, risk assessment and environmental decontamination. 


\subsection{Feedback questionnaires}

We used the same feedback questionnaire at UAH, USP-CEU and DMU, which have a Likert scale and free form response questions, and a SWOT analysis at UAH to determine the success of the introduction of the CRNT in this training. The validated feedback questionnaire was based on the questionnaire described in Peña-Fernández et al. (2015) [9]. They were completed during the last 10 minutes of the session. Ethical approval was provided by the Research Ethics Committee at DMU (Ref. 1729).

\section{RESULTS \& DISCUSSION}

\subsection{Student feedback at UAH}

Previously to modify the training and deliver to the programmes at USP-CEU and DMU, we tested the training with postgraduate pharmacists enrolled in the UAH specialty in 2015/16. The modifications undertaken produced high levels of student satisfaction. Briefly, $100 \%$ of students reported that the CRNT facilitated the understanding of the training and the selection of recovery options to respond to the case scenario proposed. Students described as a strength that the workshop was very interesting, interactive and novel, and its execution in English (as the training was delivered at the Spanish university $(\mathrm{UAH})$. The possibility of working in environmental toxicology and decontamination was described as an opportunity. Students highlighted as weaknesses and threats its relative lack of relation with the pharmaceutical industry and brief duration (5 hours).

\subsection{Student feedback at CEU and DMU}

The specific feedback-questionnaire distributed in both academic arenas have provided the following results: $85.7 \%$ (USP-CEU) and 50\% (50\% neither agree nor disagree; DMU) of students enjoyed the workshop provided (Fig. 1).
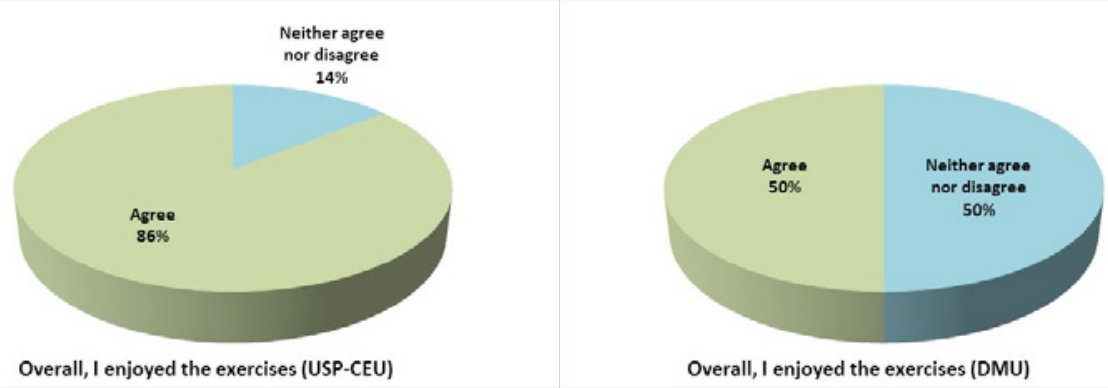

Figure 1. Student enjoyment (\%) on the training in each programme. Absence of a Likert category indicates no responses for that category.

Similar percentages were found in both programmes related with how to respond to the scenario proposed to protect human health and the environment. Thus, $83 \%$ of the Master's students (DMU) and $86 \%$ of undergraduate students (USP-CEU) reported that they learnt how to tailor an appropriate recovery plan (Fig. 2), i.e. being able to select appropriate recovery options to decontaminate the open water and urban environments proposed. Also, $83 \%$ of Master's students highlighted that they learnt how to establish some public health interventions to protect human health, all undergraduate students at USP-CEU reported that they were capable of this. 


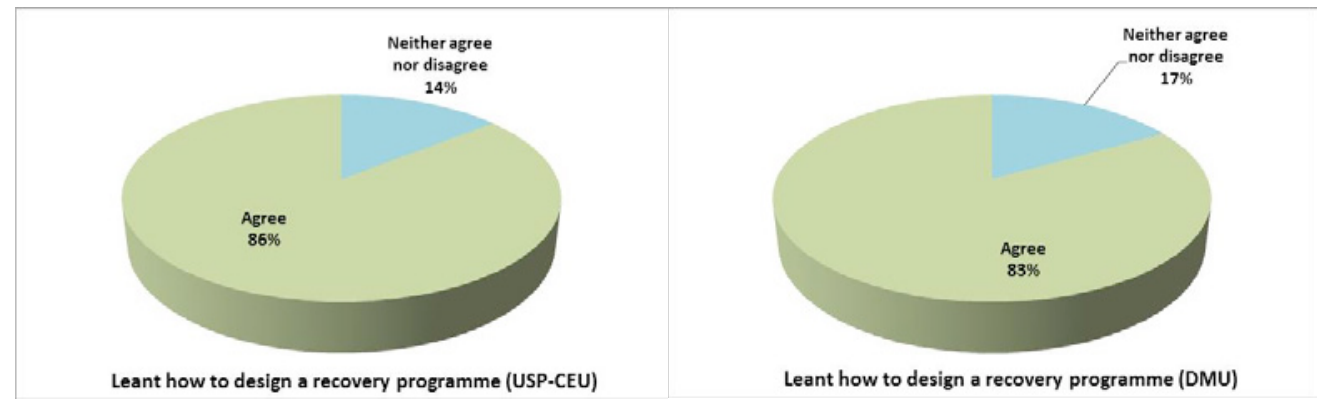

Figure 2. Student's learnt (\%) on how to tailor a recovery plan in each programme. Absence of a Likert category indicates no responses for that category.

Regarding the novel recovery tool developed by PHE, similar percentages of students in both academic arenas reported that the CRNT aided their learning about environmental decontamination and recovery (Fig. 3).

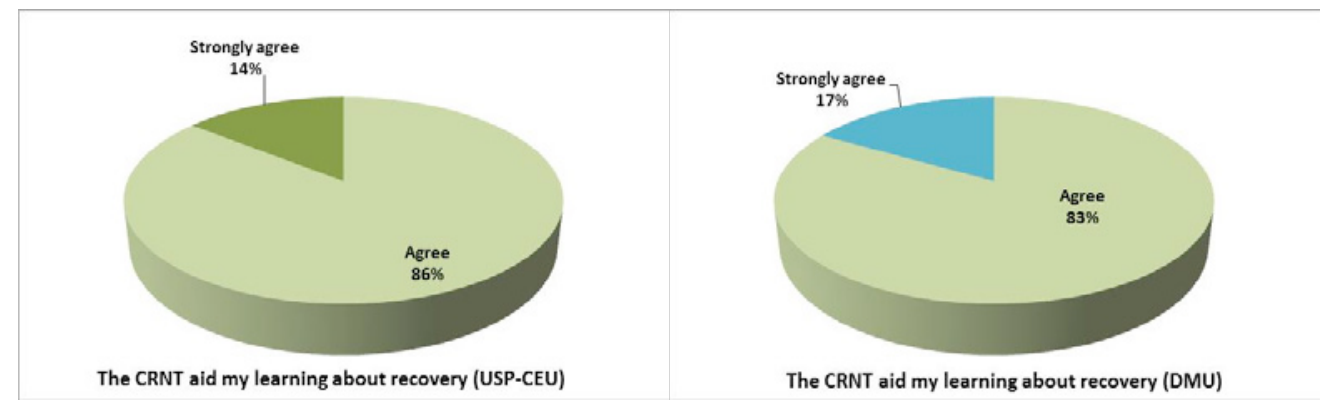

Figure 3. Student's opinion (\%) on how the CRNT aided their learning about environmental decontamination and recovery. Absence of a Likert category indicates no responses for that category.

In addition, similar percentages of students also indicated that the completion of the training, even though of short duration, resulted in an incremental increase in their knowledge and understanding in environmental toxicology and decontamination (Fig. 4): $86 \%$ (agree) of undergraduate students and $88 \%$ (50\% agree, $33 \%$ strongly agree) for USP-CEU and DMU programmes, respectively.
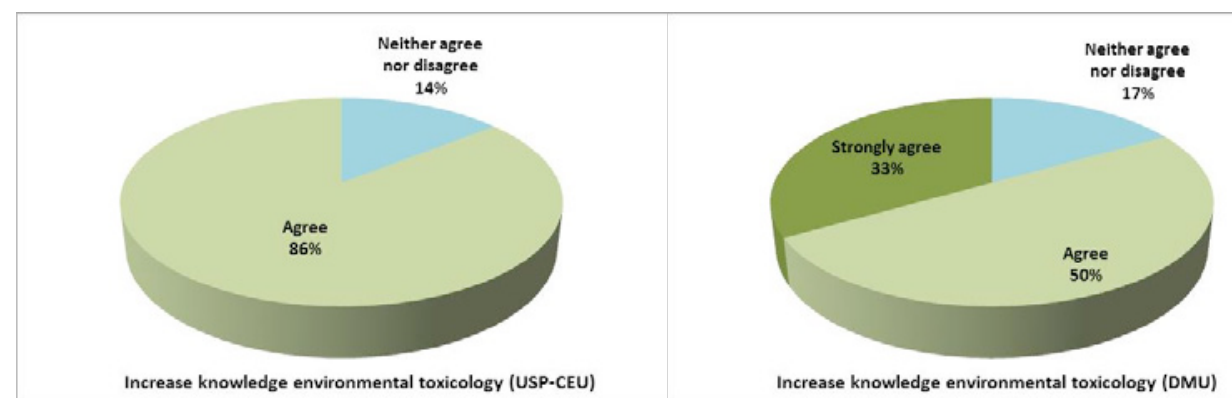

Figure 4. Student's opinion (\%) on their learning on environmental decontamination and recovery after the training. Absence of a Likert category indicates no responses for that category.

Finally, $42.9 \%$ (57.1\% neither agree nor disagree) and $83 \%$ of students have recommended the incorporation of more similar training in each programme respectively (USP-CEU and DMU).

\section{CONCLUSIONS}

The short training described in this paper has been shown to be effective in improving students' knowledge and skills to restore environments impacted by chemical agents. Although these results should be considered preliminary, we consider that the short training described here could be adapted to any human health undergraduate programme to train students how to tailor a basic recovery and 
decontamination plan to respond to chemical incidents and/or to tackle environments impacted by chemical pollutants. This type of training would be necessary due to the increasing use of toxic and carcinogenic chemicals by people and industries around the world, which can cause severe impacts on human health.

\section{ACKNOWLEDGEMENTS}

Disclaimer: the views in this article are those of the authors, not Public Health England. The authors would like to express their sincere appreciation to Professor Raquel Duarte-Davidson (PHE), Dr. Stacey Wyke (PHE), Dr. Carmen Perez Garcia (USP-CEU), Dr. Carmen Gonzalez Martin (USP-CEU). Moreover, we would like to thank the Erasmus+ staff mobility funds granted (2016-17) to Dr. PeñaFernández.

\section{REFERENCES}

[1] Wyke-Sanders S, Brooke N, Dobney A, Baker D,Murray V. The UK Recovery Handbook for Chemical Incidents. Version 1. Available at: https://www.gov.uk/government/publications/ukrecovery-handbook-for-chemical-incidents-and-associated-publications [accessed 18/09/2017].

[2] PHE, 2015. Chemical recovery navigation tool (CRNT). Available at: https://www.gov.uk/government/publications/chemical-and-radiation-recovery-navigation-tool-crrnt [accessed 18/09/2017].

[3] Drobne D. Toxicology has to use opportunities given by Bologna reform of higher education. Toxicol Lett. 2009; 190(2):116-122.

[4] Barchowsky A, Buckley LA, Carlson GP, et al. The Toxicology Education Summit: building the future of toxicology through education. Toxicol Sci. 2012; 127(2):331-338.

[5] Duffus JH. Distance learning in toxicology: resident and remote; Scotland, IPCS, IUPAC, and the world. Toxicol. Appl. Pharmacol. 2005; 207(2 Suppl):746-749.

[6] Nadal, M., Rovira, J., Díaz-Ferrero, J., Schuhmacher, M., Domingo, J.L. (2016). Human exposure to environmental pollutants after a tire landfill fire in Spain: Health risks. Environ Int, 97, 37-44.

[7] Peña-Fernández A., Wyke S., Brooke N., Duarte-Davidson R. Factors influencing recovery and restoration strategies following a chemical incident. Environment International 2014; 72:98-108.

[8] Wyke S, Peña-Fernández A, Brooke N, Duarte-Davidson R. The importance of evaluating the physicochemical and toxicological properties of a contaminant for remediating environments affected by chemical incidents. Environ Int 2014;72:109-18.

[9] Peña-Fernández A., González-Muñoz MJ., Peña MA. Designing training for teaching environmental toxicology to specialized pharmacists. Currents in Pharmacy Teaching and Learning 2015; 7:864-868.

[10] Peña-Fernández A., Evans MD., Magnet A., Izquierdo F., del Águila C. Introducing training to respond to chemical incidents in the pharmacy degree at the University of San Pablo CEU (Spain). EduLearn Proceedings 2017; 5086-5091.

[11] Escalera B., Peña MA., Evans MD., Peña-Fernández A. Implementation of chemical incident training in human health programmes. In: Research in university teaching. Designing the future from educational innovation. Editorial Octaedro. ISBN: 978-84-9921-935-6. In press. 